\title{
LAPAROSCOPIC RADICAL PROSTATECTOMY BY EXTRAPERITONEAL ACCESS WITH DUPLICATION OF THE OPEN TECHNIQUE
}

\author{
M. TOBIAS-MACHADO, PEDRO FORSETO JR., JIMMY A. MEDINA, MARCELO \\ WATANABE, ROBERTO V. JULIANO, ERIC R. WROCLAWSKI \\ Discipline of Urology, Medicine School of ABC, Santo André, São Paulo, Brazil
}

\begin{abstract}
Introduction: The laparoscopic radical prostatectomy is a continually developing technique. Transperitoneal access has been preferred by the majority of centers that employ this technique. Endoscopic extraperitoneal access is used by a few groups, nevertheless it is currently receiving a higher acceptance. In general, the antegrade technique is used, with dissection from the bladder neck to the prostate apex.

The objective of the present paper is to describe the extraperitoneal technique with reproduction of the open surgery's surgical steps.

Surgical Technique: With this technique, the dissection of the prostate apex is performed and, following the section of the urethra while preserving the sphincteric apparatus, the Foley catheter is externally tied and internally recovered, which allows cranial traction, similarly to the way it is performed in conventional surgery. The retroprostatic space is posteriorly dissected and the seminal vesicles are identified by anterior and posterior approach, obtaining with this method an optimal exposure of the posterolateral pedicles and the prostate contour. The initial impression is that this technique does not present higher bleeding rate or difficulty level when compared with antegrade surgery. Potential advantages of this technique would be the greater familiarity with surgical steps, isolated extraperitoneal drainage of urine and secretions and a good definition of prostate limits and lateral pedicles, which are critical factors for preserving the neurovascular bundles and avoiding positive surgical margins. A higher number of cases and a long-term follow-up will demonstrate its actual value as a technical option for endoscopic access to the prostate.
\end{abstract}

Key words: prostatic neoplasms; prostatectomy; laparoscopy

Int Braz J Urol. 2004; 30: 221-6

\section{INTRODUCTION}

Laparoscopic radical prostatectomy has become an option for treatment of localized prostate cancer in some centers. The majority of laparoscopists prefer the transperitoneal technique that was standardized by Guilleneau \& Vallencien (1).

The endoscopic extraperitoneal technique performed by some groups promotes antegrade dissection, from the bladder neck to the prostate apex (2-4). Our objective was to describe the extraperitoneal technique that was initiated in our institution in 2002 with duplication of open surgery's surgical steps, discussing potential advantages and initial impressions obtained after its use in 25 patients.

\section{SURGICAL TECHNIQUE}

1. Patient is positioned in horizontal dorsal decubitus, with Y-shaped abduction of lower limbs on the table; 
2. Display of the surgical team. The surgeon operates on the left side, the camera is positioned at the upper end of the table, and the assistant stand at the patient's right side. During suture, for improved comfort, the surgeon and the camera switch places;

3. Umbilical incision measuring $1.5 \mathrm{~cm}$ up to the Retzius space;

4. Creation of extraperitoneal space through digital dissection and modified balloon dilator (handicraft);

5. Hasson trocar $(10 \mathrm{~mm})$ through the umbilical incision for the 0-grade optics;

6. Installation of pneumoretroperitonium with $\mathrm{CO}_{2}$ tension of $15 \mathrm{mmHg}$;

7. Introduction of another 4 working trocars $(2$ pararectal external measuring $10 \mathrm{~mm}$, and 2 in iliac fossa measuring $5 \mathrm{~mm}$ ) under direct view, in an arciform shape, taking care in order to avoid peritoneal lesion (Figure-1);

8. Exeresis of pre-prostatic fat with monopolar cautery for proper identification of prostate, bladder and puboprostatic ligaments;

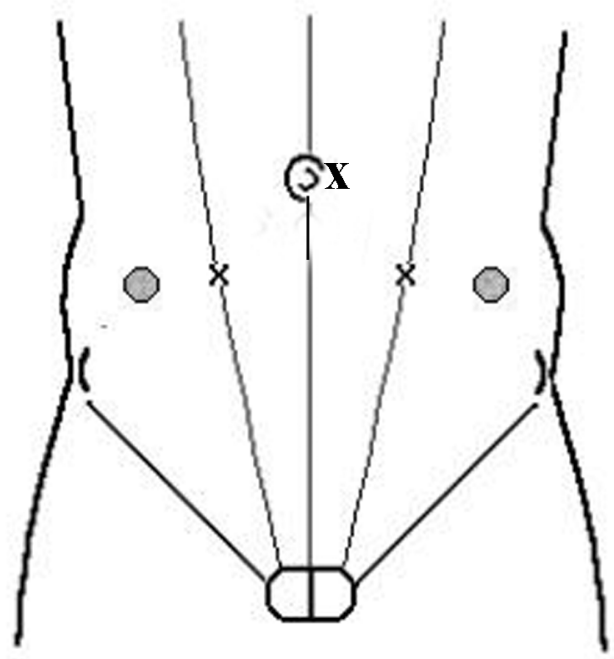

\section{RADICAL PROSTATECTOMY}

Figure 1 - Display of trocars in arciform shape. The 0-grade optics is placed in the umbilical trocar. Two pararectal $10-\mathrm{mm}$ ports and another 25 -mm ones in iliac fossa complete the access. $O=5-m m$ trocar, $X=10-m m$ trocar
9. Bilateral opening of endopelvic fascia with scissors, following previous contralateral traction of the prostate (Figure-2);

10. Identification and sectioning of puboprostatic ligaments (Figure-3);

11. Vascular control of dorsal vein complex of the penis with a X-stitch using 2-0 polyglactine suture with CT-1 needle (Figure-4) and control of the retrograde blood flow with harmonic or bipolar scalpel, or polymer clip (Hem-o-lock®) (Figure 5). Applying the clip makes the subsequent identification of the bladder neck easier for reconstruction, a surgical step that is often arduous when we choose to preserve the bladder neck;

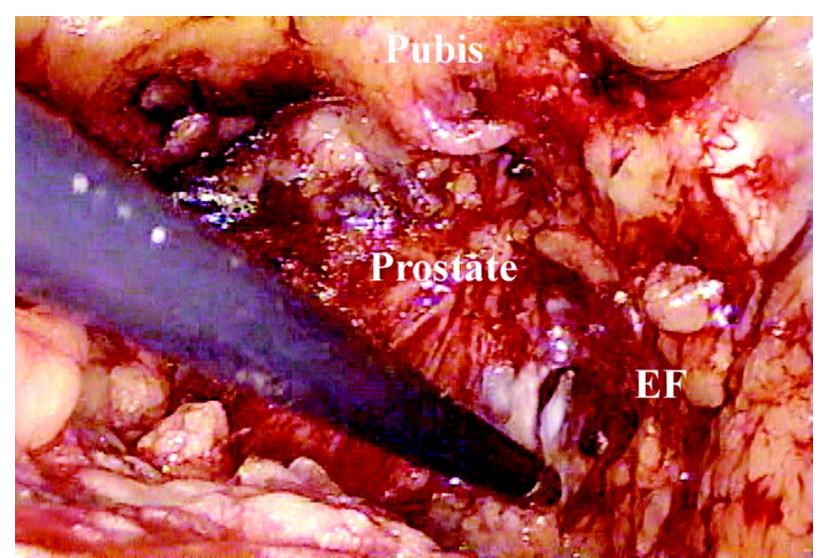

Figure 2 - Opening of endopelvic fascia (EF). The assistant pulls the prostate to the contralateral side and the surgeon sections the endopelvic fascia with scissors.

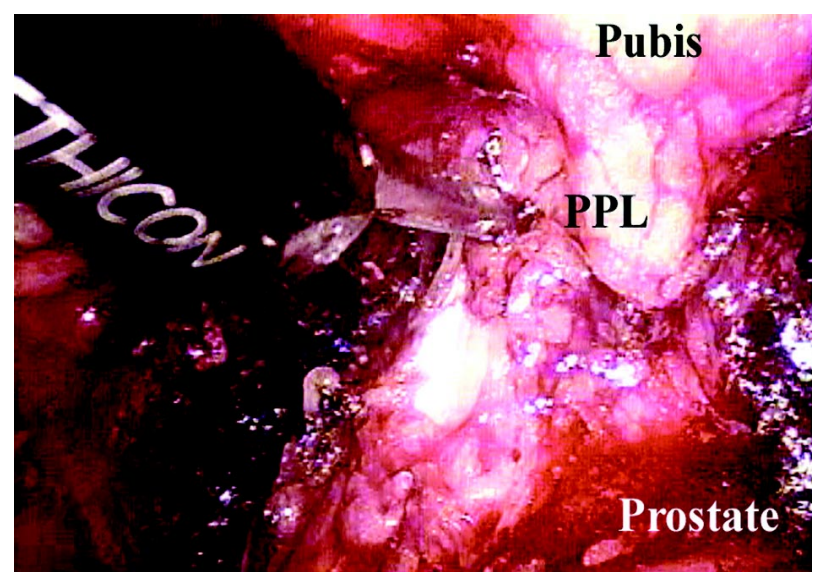

Figure 3 - Sectioning of the puboprostatic ligament (PPL) with harmonic scalpel. 


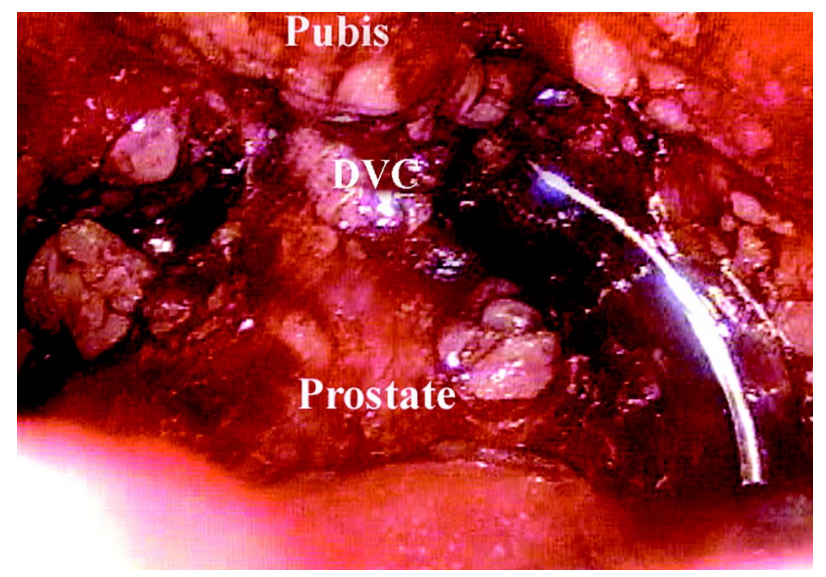

Figure 4 - Vascular control of the dorsal vein complex (DVC).

12. Apical dissection with preservation of the sphincteric apparatus;

13. Sectioning of the dorsal vein complex of the penis with electrocautery or harmonic scalpel, until the urethra is viewed (Figure-5);

14. Opening of the urethral anterior wall with scissors (Figure-6). Section is performed after perfectly identifying the limits of the prostate apex and urethra, thus avoiding positive margins;

15. The catheter balloon is filled with $20 \mathrm{~mL}$ of distilled water. The Foley catheter is externally pulled for subsequent knot application with 0-cotton suture including drainage and balloon routes;

16. Sectioning of the catheter close to the previously applied knot;

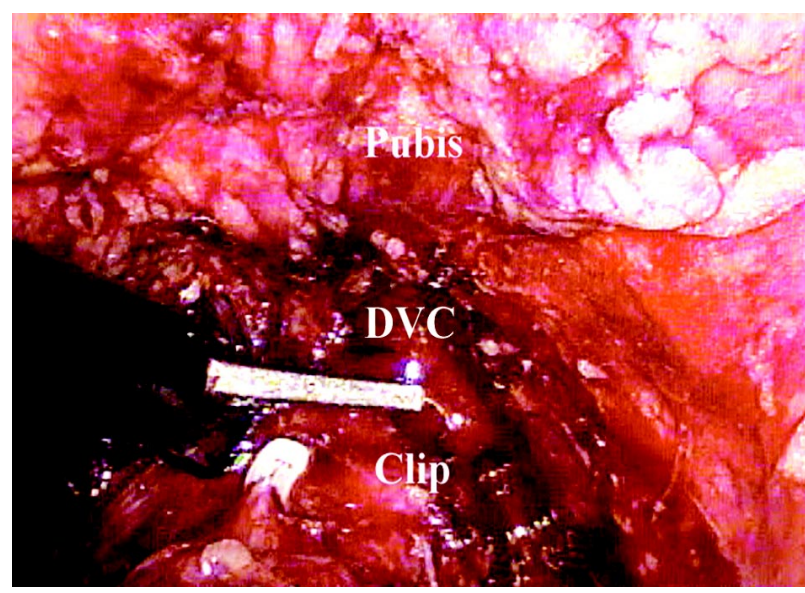

Figure 5 - Sectioning of dorsal vein complex with harmonic scalpel. Ligation of dorsal vein complex $(D V C)$ with suture.
17. Recovery of the remaining stump of the Foley catheter, through endoscopic view in the extraperitoneal space (Figure-7);

18. Posterior section of the urethra and recto-urethral muscle following cranial traction of the stent by the assistant;

19. Blunt retroprostatic dissection up to the most proximal point as feasible;

20. Identification and opening of the posterior layer of the Denovilliers fascia (Figure-8). At this time it is possible to identify the pre-rectal fat. Analogically to open surgery, we know that the neu-

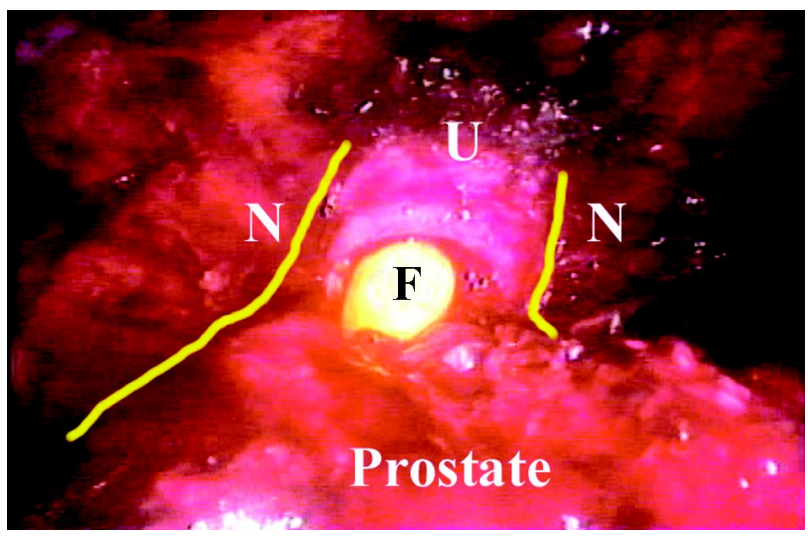

Figure 6 - Opening of the urethral anterior wall. Observe the Foley catheter $(F)$ and the prostate apex, clearly identified. The path of the nervi erigentes $(N)$, schematically identified with yellow lines, is located laterally to the sectioning area in the urethra $(U)$.

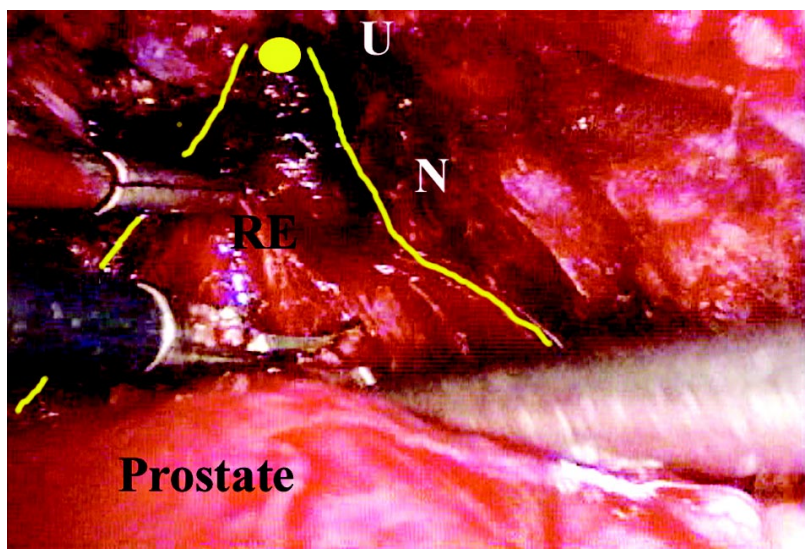

Figure 7 - Dissection of retroprostatic space. $U=$ urethra (yellow circle), $R E=$ retroprostatic space, $N=$ projection of nervi erigentes (yellow line). 


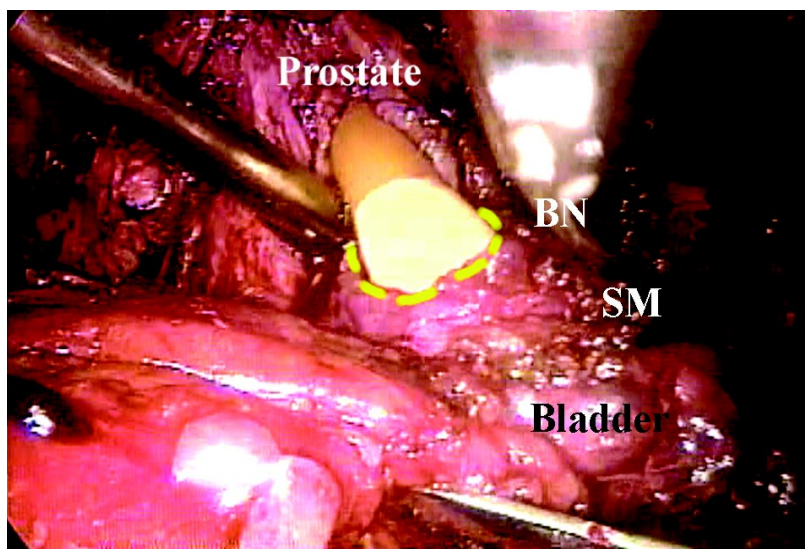

Figure 8 - Sectioning of bladder neck with harmonic scalpel preserving muscular fibers. As a result, we obtained a small diameter neck (dotted line), which makes future vesicourethral anastomosis easier. $B N=$ bladder neck, $S M=$ muscle fibers.

rovascular bundle lies laterally and under the fascia, which makes nervous preservation easier during ligation of the prostatic pedicle, which is performed by posterior access;

21. Sectioning of the bladder neck, with preservation of muscular fibers whenever possible. The dissection is started with harmonic or bipolar scalpel and upon reaching the urethral mucosa, it is sectioned with scissors (Figure-9);

22. Identification and opening of the anterior layer of Denovilliers' fascia, posterior to the prostate with visualization of vasa deferentia;

23. Identification and sectioning of vasa deferentia with harmonic or monopolar scalpel;

24. Superior traction of the vasa deferentia by the assistant in order to release the seminal vesicles. At this time, we preferred to use harmonic or bipolar scalpel in order to avoid dissipation of thermal energy that could damage the nervi erigentes;

25 . The assistant performs the lateral and superior traction of previously mobilized (released) prostate, enabling the clear identification of the prostatic pedicles and the prostate capsular limits. The control of the prostatic pedicles is performed with harmonic or bipolar scalpel. Alternatively polymer clips (Hem-o-lock $®)$ can be used (Figure10);

26. Exeresis and entrapment of the specimen that is located in right iliac fossa;

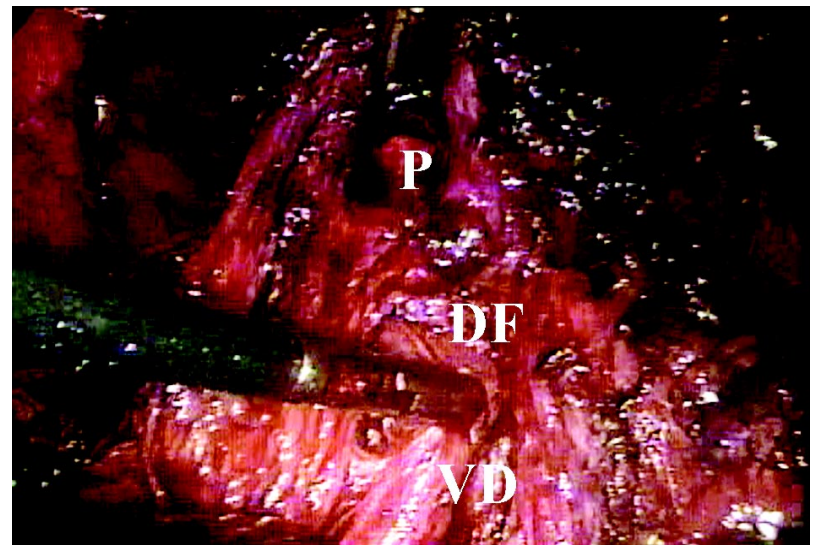

Figure 9 - Identification and opening of the anterior layer of Denovilliers' fascia posterior to the prostate with viewing of vasa deferentia. $P=$ prostate, $D F=$ Denovilliers' fascia, $V D=$ vas deferens.

27. Vesicoureteral anastomosis is initiated with the patient in Trendelemburg position in order to improve the visualization of the urethra. The surgeon works with the pararectal $10-\mathrm{mm}$ trocars at the upper end of the table. We perform a continuous 3-0 polyglecaprone (monocryl@) suture with $\mathrm{SH}$ needle. We use two 13-cm sutures, one colorless and the other one violet, externally tied by the distal end. Suture begins at 6 o'clock position in the bladder directed inwards and each of the sutures rises toward 12 o'clock position, where a single internal knot is made (5);

28. Drainage with Penrose though one of the 5-mm ports;

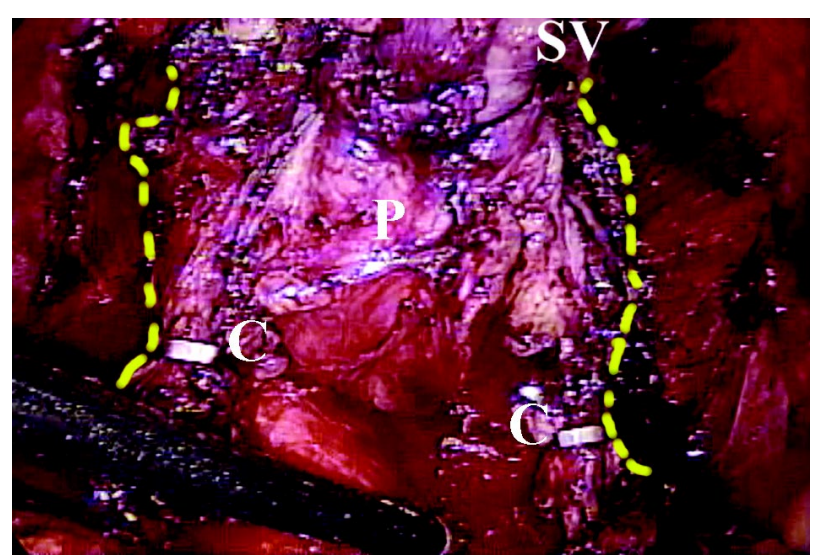

Figure 10 - The prostatic pedicles are identified and clipped. $P=$ prostate. $C=$ polymer clip. Observe the path of the nervi erigentes (dotted lines). $S V=$ seminal vesicle. 
29. Removal of the specimen by enlargement of the umbilical port and closure of the incisions;

\section{COMMENTS}

Laparoscopic radical prostatectomy is a laborious procedure with a long learning curve. The most significant series in literature, where it was possible to standardize and systemize the technique, use transperitoneal access (1).

The endoscopic extraperitoneal technique was initially described by Raboy et al. where, after creating the space and ligating the dorsal vein complex, the dissection was performed from the bladder neck to the prostate apex (antegrade). The author reported that this technical option resulted from the higher possibility of bleeding and technical difficulty if the early sectioning of the complex was performed (2). This observation is contrary to the results obtained in our initial series of 25 patients, where none required hemotransfusion or conversion to open surgery.

In our setting, Andreoni et al. were the first authors to report laparoscopic radical prostatectomy using the antegrade technique (3). Potential advantages of the extraperitoneal access are the non-manipulation of abdominal viscera, reducing the risk of direct or distant lesions, keeping the drainage of secretions isolated from the peritoneal cavity, greater familiarity with local anatomy, with the Trendelemburg exaggerated position being unnecessary (frequently required in the transperitoneal technique). As disadvantages it presents a working space with lower gas content, requiring greater adaptation for instrument movements and aspiration of secretions and smoke. If the space is not properly developed in its lateral area, according to previous descriptions, a higher tension in the vesicoureteral anastomosis can occur. Peritoneal perforation hampers, but does not prevent the surgery from being completed. If the progression in dissection is hard, it is possible to operate by transperitoneal approach following wide peritoneal opening (2-4).

Our initial impression is that transperitoneal and extraperitoneal techniques are equivalent concerning surgical time, blood loss, complications and post-operative recovery. However, in the extraperitoneal technique, the presence of urinary fistula shows a better outcome, since there is no urine drainage to the peritoneal cavity, thus avoiding prolonged paralytic ileus.

As original modifications, in addition to the retrograde dissection as described in the open technique, we used a polymer clip in order to avoid venous reflux from the dorsal complex, which aids in the subsequent identification of the bladder neck during suture. The external handling and sectioning of the Foley catheter enabled the internal and superior traction by the assistant, similarly to the open technique for accessing the posterior aspect of the prostate. Such dissection makes the identification of lateral prostatic pedicles quite easier following the dissection of the bladder neck. The accurate identification of the prostate limits is fundamental for a proper preservation on the neurovascular bundles and to avoid the occurrence of positive margins.

Recently, Dubernard et al. (2003) described the first series of 143 patients using retrograde laparoscopic extraperitoneal technique. The authors conclude that in spite of presenting only preliminary functional results, the technique is promising and can potentially become the method of choice for laparoscopic radical prostatectomy (5).

From this initial work, we concluded that extraperitoneal access is feasible, being possible to practically duplicate surgical steps of the open surgery. The actual role and advantages of this surgery when compared with laparoscopic transperitoneal technique waits for future assessments in prospective studies with a higher number of cases.

\section{REFERENCES}

1. Guillonneau B, Vallancien G: Laparoscopic radical prostatectomy: the Montsouris technique. J Urol. 2000; 163: 1643-9.

2. Raboy A, Ferzli G, Albert P: Initial experience with extraperitoneal endoscopic radical retropubic prostatectomy. Urology. 1997; 50: 849-53.

3. Andreoni C, Gattas N, Srougi M: Initial experience with extraperitoneal endoscopic radical retropubic prostatectomy. Int Braz J Urol. 2001; 27: 563-5.

4. Bollens R, Bossche MV, Roumeguere TH, Damoun A, Ekane S, Hoffmann P, et al.: Extraperitoneal 
laparoscopic radical prostatectomy. Eur Urol. 2001; 40: 65-9.

6. Dubernard P, Benchetrit S, Chaffange P, Hamza T, Van Box, Som P.: Retrograde extraperitoneal laparoscopic prostatectomy (R.E.I.P). Simplified technique (based on a series of 143 cases). Prog. Urol. 2003; 13: 16374.

Received: December 2, 2003

Accepted after revision: May 31, 2004

\section{Correspondence address:}

Dr. Marcos Tobias-Machado

Rua Graúna, 104 / 131

Moema, São Paulo, SP, 04514-000, Brazil

Fax: + 5511 5533-5227

E-mail: tobias-machado@uol.com.br 